\title{
All-staff Oriented International Postgraduate Education Model
}

\author{
Wen Zhang ${ }^{1, a}$, Xin Yuan ${ }^{1, b,{ }^{*}, \text { Qiang Zhang }}{ }^{2, c}$ \\ ${ }^{1}$ College of Automation, Harbin Engineering University, Harbin China \\ ${ }^{2}$ Science and Technology on Underwater Vehicle Laboratory, Harbin Engineering University, Harbin \\ China \\ azhangwen@hrbeu.edu.cn, byuanxin@hrbeu.edu.cn, czhangqiang103@hrbeu.edu.cn \\ ${ }^{*}$ Corresponding author
}

Keywords: Internationalization, Postgraduate education, All-staff oriented.

\begin{abstract}
In view of the fact that China's postgraduates' internationalization education has a small audience and does not go deep into it, from the perspective of all graduate students and teachers, with the purpose of international education deepening through all aspects of graduate training, a graduate-oriented global education model for all graduates is proposed. It also aims to investigate the development path of all-staff oriented internationalization education of all postgraduates through construction of a diversified and independent international cooperative communication training mechanism, and establishment of an internationalized curriculum for all postgraduates, as well as establishment of an international teaching and research team for all teachers, and the establishment of an international education assessment system for all staff.
\end{abstract}

\section{面向全员的研究生国际化教育模式研究}

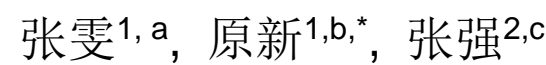

1哈尔滨工程大学自动化学院, 哈尔滨, 黑龙江, 中国

2哈尔滨工程大学水下机器人技术重点实验室, 哈尔滨, 黑龙江, 中国

azhangwen@hrbeu.edu.cn, byuanxin@hrbeu.edu.cn, czhangqiang103@hrbeu.edu.cn

通讯作者

关键词：国际化; 研究生教育; 面向全员

中文摘要.针对我国研究生国际化教育受众少、不深入的问题, 从全体研究生和教师的角度出 发, 以国际化教育深入贯穿研究生培养的各环节为目的, 提出了面向全员的研究生国际化教 育模式。并通过构建多元化的自主国际合作交流培养机制、面向全体学生建设国际化课程、 面向全体教师建设国际化教学科研团队、建立全员国际化的教育测评体系四项措施, 面向全 员探索国际化研究生教育的发展途径。

\section{1. 引言}

随着全球一体化的加速，高等教育国际化成为一种必然趋势和要求 ${ }^{[1-3]}$, 研究生教育国际 化已然成为有效提升研究生创新意识和能力的重要途径。在这种全球化的大趋势下各大高校 纷纷走上了研究生教育的国际化路径 ${ }^{[4]}$, 然而目前我国大部分高校的研究生国际化培养仅仅 停留在一个比较初级的阶段, 即招收少量国外留学生来校学习、邀请少量国外教授专家来校 
讲学、选派少量研究生出国培养。目前每所高校每年选派的学生数占全体学生总数的比例不 足 $1 \%$, 研究生在国内参与的国际交流活动不足4次/年。我国目前的研究生国际化教育模式费 用高、受众少, 只能是 “贵族式” 的教育, 不利于培养自身国际化的师资队伍, 难以实现 “培 养大批具备国际化意识、国际化知识、国际化创新科研能力人才” 的目标 ${ }^{[5]}$ 。在 “双一流” 建设的新形势下，研究生教育国际化向 “大规模、常态化、成建制、交互式、多层次” 已成 为必然趋势。因此研究国际化的研究生教育方式, 促进研究生国际化培养面向全体学生和教 师，对我国研究生教育的国际化持续发展有重要意义。

\section{2. 面向全员的研究生国际化教育内涵}

面向全员的研究生国际化教育是指在全部学生群体和全部教师全体中实施研究生国际化 教育, 它包含两层含义: 第一, 面向全员的研究生国际化教育不是小众教育模式, 它不是仅 仅通过选派几个研究生出国培养或选派几名教师出国访学就能实现的, 而是要让全体学生和 全体老师都参与到国际化教育当中来。第二, 面向全员的研究生国际化教育不是一种偶尔教 育模式, 它不是通过偶尔几次国际交流就能实现的, 它要求国际化教育贯穿于研究生教育全 过程中、体现在研究生教育的每个环节中 ${ }^{[6]}$ 。

\section{3. 面向全员的研究生国际化教育模式研究}

针对我国研究生国际化教育受众少的问题, 从培养机制、课程设计、教师团队建设和教 育测评体系四个方面提出改进措施，构建面向全员的研究生国际化教育模式。

\section{1 构建多元化的研究生自主国际合作交流培养机制}

随着信息时代的快速发展, 国外很多学者的最新研究细节和成果以各种形式公布于网上, 为研究生紧跟国际研究前沿、与国际专家交流提供了多种渠道。教育的关键在于 “授人以渔”, 因此国际化的国际交流培养不能只停留在为学生提供国际合作交流的机会上, 更重要的是培 养学生自主发现相关研究的国际团队和学者能力、建立与国际学者的交流的能力 ${ }^{[7]}$ 。只有具备 自主国际合作交流意识的学生才是真正意义上的国际化人才。可以通过如下举措构建多元化 的研究生自主国际合作交流培养机制

(1) 将国际交流培养贯穿于课程教学和科研中，培养学生的自主国际交流意识和能力

增设科研检索课程或讲座系统的向学生介绍寻找研究相关领域的国际科研团队和学者的 途径、跟踪国外相关研究的方式、与国际学者取得联系的方法。增设国际交流语言与礼仪课 程或讲座培养学生进行国际交流的基本素养; 在科研过程导师和团队不断向学生渗透国际化 意识, 引导学生在科研检索和文献阅读过程中自主挖掘国际合作交流的方式和方法, 要求学 生用英文撰写、发表论文, 用英语进行研讨, 鼓励学生通过邮件等方式与相关领域的国际学 者进行讨论 ${ }^{[8]}$ 。

(2) 举办国际化的国内学术交流活动, 为学生提供更多的国际交流训练机会

采用国际化的方式定期举办国内学术论坛或讲座, 邀请国外学者或留学生参与, 为学生 创造国际化的研讨环境, 锻炼学生的国际交流能力。

举办全英文研究生学术成果墙报展, 邀请全院师生参观、交流、点评以及打分。要求研 究生用英文制作墙报、英文讲解, 与参观者之间的讨论也用英文进行, 锻炼研究生的英文学 术表达与交流能力, 也为学生走向国际学术交流舞台提供练习机会。

(3) 开展多元化的国际合作交流, 为学生提供更多的国际交流实践

一方面, 通过组团访问、参加国际学术会议、著名大学联合培养、短期助研学术交流等 多种方式为学生提供更多、更深入的国际交流实践机会。另一方面, 为了支撑学生的自主国 际交流能力培养, 制定方案对学生自主挖掘的国际交流途径进行审查, 对于审查结果合格的 
自主挖掘国际交流途径, 由学校或导师出资进行实施。学生自主挖掘国际交流途径不但有益 于学生国际意识和国际交流能力的培养, 同时也是扩展学校和导师国际视野的机遇。

\section{2 建设全员国际化的课程}

课程是培养目标的具体实施, 是面向全体学生的。因此建立全员国际化的课程是普及国 际化研究生教学的基础。首先建立全员国际化的的课程需要整合和调整课程教学内容和学时、 融合国际科研成果。调研国外研究生课程建设情况, 分析国外课程与培养目标实际达成度之 间的关系, 在课程建设中引入和吸取国外的先进经验, 紧跟学科的国际发展情况, 结合我国 研究生教育的实际情况, 面向全体学生设计与国际接轨的先进课程。

其次, 推行国际化的教学方式也是建设国际化的课程的重要内容。国外的课程教育以学 生为主体, 注重培养学生的学习能力, 教学方法通常灵活多样, 包括启发式、探究式、讨论 式 ${ }^{[9]}$ 。我国课程教学模式存在重理论轻实践、重知识传授轻能力培养的问题, 需要不断的吸 取国外的先进的教学方式, 是我国的研究生教育更倾向于提高学生对知识的自我理解能力, 培养他们通过阅读文献总结学科发展热点及掌握学。

再次, 国外的课程教育紧跟科学技术的发展, 近些年慕课、微课、移动终端课程等利用 现代科技的教学手段层出不穷, 这些先进的手段不但为教学提供了更便捷的工具, 而且能够 提高教学效率、激发学生的学生兴趣。国际化课程需要融入国际化的先进教学手段, 使我国 研究生课程不但在课程设置和内容上站在国际学术研究前端, 而且在学习手段上也站在国际 科技发展的前端。

此外，国际化的课程不应仅仅停留在效仿国际先进课程设置、跟踪国际教学方式、手段 上, 更需要结合我国前端科研成果开创世界领先的国际化课程, 甚至让国外研究生教育效仿 我国的先进课程。在国际化课程建设方面我们要逐步走出一条由效仿国际、走向国际到最终 处于国际领先地位的道路。在开创国际先进课程方面, 清华大学与学堂在线联合推出的雨课 堂就是很好的例子。雨课堂以我国移动应用服务技术研究成果为基础, 是一项国际领先的教 学辅助软件, 目前正在国内广泛使用, 同时正在向国际推广。

\section{3 建设国际化的教学科研团队}

科研团队是我国高等学校特别是研究型大学从事科学研究的一种重要的模式, 有利于学 科交叉和优势互补, 有利于承担重大项目和出大成果 ${ }^{[10]}$ 。建设国际化的教学科研团队有利于 培养新的学科生长点并加速其成长, 为具有国际化视野的研究生培养创造更为优越的环境。

建设国际化的教学科研团队首先要激励教学科研团队的每位教师提高自身的国际化水 平。一方面提供更多的出国进修访学机会, 并要求教师回国后启动双语教学的建设和校级精 品课的建设。另一方面将教师的国际化水平列入教师考核机制中, 促使每位教师都积极的参 与到国际化建设中。

其次, 建设国际化的教学科研团队要面向世界知名大学招聘人才。在引进人才时, 对于 有海外留学背景的人才优先录取, 这样能极大地改善教师的学缘结构, 增强学校的知名度和 国际化程度。通过采用双语教学进行授课, 反过来也会吸引更多的留学生来校交流, 有利于 提升本专业国际化办学的氛围。

\section{4 全员国际化的研究生创新教育测评体系}

教育测评是对教育的评价和经验教训总结, 是形成反馈提升教育效果、促进教育目标达成 的重要环节 ${ }^{[11]}$ 。研究生创新教育要在全员国际化路径上持续发展, 就必须制定突出全员国际 化目标的教育测评体系。全员国际化目标的教育测评体系可在常规的测评体系的基础上, 增 加衡量学生的国际化意识、国际化知识和国际化创新科研能力的指标。基于多指标综合评价 理论, 采用层析分析法构建全员国际化的研究生创新教育测评指标体系, 采用专家打分的方 式确定个评价指标的权重, 最终给出全员国际化的研究生创新评估方法。 


\section{4. 结束语}

研究生教育的国际化是发展的必然趋势, 而国际化研究生教育的质量取决于国际化的普 及率和渗透程度。高质量的国际化研究生教育应惠及每名学生和每位老师, 应渗透于研究生 教育的每个环节。而长期以来我国的研究生国际化教育存在小众收益和偶尔国际化的问题, 这种情况严重制约了我国研究生教育的发展。针对我国研究生国际化教育中出现的问题, 本 文以加深研究生教育的国际化程度为目的, 提出了面向全员的研究生国际化教育模式, 并从 培养机制、教师团队建设、课程设计和教育测评体系四各方面给出了具体措施。

\section{致谢}

本文为黑龙江省教育科学规划青年专项课题《面向全员的研究生国际化教育模式研究与 实践》（GBD1317119）、哈尔滨工程大学教学改革研究项目《基于雨课堂的翻转课堂教学模 式研究及实践》(JG2017B07Z)和哈尔滨工程大学教育教学改革研究项目《国际化视野下研究 生创新人才培养探索与实践》（JG10217Y10）的阶段性成果之一。

\section{References}

[1] M Theodore, International education: Its history and promise for today, Praeger, vol. 13, pp.4, 1994.

[2] C. Kerr, the internationalization of learning and the nationalization of the purpose of higher education: two "laws of motion" in conflict, European Journal of Education, vol. 1, pp.7, 1990.

[3] H. D. Wit, Internationalization of higher education in the United States of America and Europe: A historical, comparative and conceptual analysis, Westport CT: Greenwood Press, pp.83-102, 2002.

[4] J. C. Reich, Global learning as general education for the twenty-first century, Educational Rresearch \& Reviews, vol. 21, pp. 468, 2012.

[5] Jianjing Yang, Jiandong Shao, Approaches to internationalization of higher vocational education under the principle of building "First-class Higher Vocational Education, Heilongjiang Researches on Higher Education, vol. 1, pp.108 -111, 2018.

[6] Knight Jane, Updated internationalization definition, International Higher Education, vol. 33, pp.108 -111, 2004.

[7] Xue Shan, Dong Li, the dynamics of internationalization of the universities, Higher Education, vol. 6, pp.6-10, 2015.

[8] M. E. Connell, J. L. Norwood, International education and foreign languages: keys to securing America' s future. National Academies, vol. 33, 2007.

[9] Qingwei SU, Baolai Cai, On general education curriculum design based on international literacy, Heilongjiang Rsearches on Higher Education, vol. 277, pp.166 -169, 2017.

[10]Huijun Gao, Shen Yin, Xuebo Yang, importance of lecturers' quality in higher education under the background of internationalization, Heilongjiang Researches on Higher Education, vol. 263, pp. 87-86, 2016.

[11]Dirk Damme, Quality issues in the internationalization of higher education, Higher Education, vol. 33, 2001. 